\title{
Effect of polymer coating on faecal recovery of ingested 5-amino salicylic acid in patients with ulcerative colitis
}

\author{
H AL MARDINI, D C LINDSAY, C M DEIGHTON, AND C O RECORD \\ From the Gastroenterology Unit, Royal Victoria Infirmary and University of Newcastle upon Tyne
}

SUMMARY It has been suggested that polymer coating might retard jejunal absorption of 5-amino salicylic acid (5-ASA) and thus promote delivery to its colonic site of action. Twenty three patients with active (nine), or quiescent (14) ulcerative colitis were given either uncoated or coated 5-ASA (Asacol) $400 \mathrm{mg}$ qds for one to three weeks, after which they ingested five $1.5 \mathrm{ml}$ dialysis membrane sachets which were recovered from the stool in the next 72 hours. After one week of treatment the concentration of 5-ASA in the faecal dialysate, urine, and fasting plasma in those receiving the coated and uncoated preparations were respectively: $25 \cdot 4 \pm 5 \cdot 1$ compared with $1 \cdot 2 \pm 0.4 \mathrm{mmol} / \mathrm{l}$ $(\mathrm{p}<0.001) ; 0.34 \pm 0.21$ compared with $0.70 \pm 0.29 \mathrm{mmol} / 24 \mathrm{~h}(\mathrm{NS})$ and $11 \cdot 1 \pm 4.2$ compared with $0.07 \pm 0.03 \mu \mathrm{mol} / 1(\mathrm{p}<0.02)$. Faecal excretion of the drug appeared to be greater in patients with active colitis than in those with quiescent disease. Thus coating with $\mathrm{pH}$ dependent methacrylic acid copolymer B is a very effective method of promoting delivery of 5-ASA to the colon, stool dialysate concentrations being 20 fold more than those in controls. Increased trough plasma concentrations in the polymer coating group probably reflect delayed intestinal absorption but no evidence of plasma accumulation after 21 days of therapy was found.

The use of sulphasalazine in the treatment of inflammatory bowel disease has been limited by side effects, mainly attributable to the sulphapyridine component.' 5-amino salicylic acid (5-ASA) is released in the colon by bacterial azoreduction of the parent molecule ${ }^{2}$ and 5-ASA is now known to be the active moiety. ${ }^{3-5}$

Because of the adverse effects of sulphapyridine, recent work has been directed towards the development of systems which enable 5-ASA to be delivered to the colon without the concomitant administration of a sulphonamide. One method is to coat 5-ASA with a pH dependent polymer (Eudragit $S$ ) designed to disintegrate in the terminal ileum when the $\mathrm{pH}$ is consistently above $7 . .^{6}$ Such a preparation has been found to be effective for maintenance of a remission of ulcerative colitis ${ }^{7-8}$ and is well tolerated by most

Address for correspondence: Dr C O Record, Royal Victoria Infirmary, Queen Victoria Road, Newcastle upon Tyne NE1 4LP

Received for publication 29 January 1987. patients experiencing side effects of sulphasalazine. ${ }^{-12}$ Radiological studies have shown the integrity of polymer coated capsules in their passage to the colon ${ }^{6}$ but the value of the coating in promoting stool excretion of 5-ASA compared with the noncoated product, is unknown. The aim of the present study was to determine the serum concentrations, urinary and faecal excretion of 5-ASA after ingestion of a polymer coated preparation (Asacol) by patients with active and inactive ulcerative colitis, and to compare values with those obtained with a noncoated product.

\section{Methods}

PATIENTS

Twenty three patients gave written consent to participate in the trial. On day 0 patients were started on either coated 5-ASA $400 \mathrm{mg}$ qds (Asacol, Tillots, UK; 15 patients) or an identical but non-polymer coated formulation (eight patients) in the same dose. 
Sulphasalazine therapy was discontinued. Six of the 15 patients on coated 5-ASA had inactive disease (defined as a normal bowel habit with no blood in the stool), while in the other nine the disease was active. All eight patients on uncoated 5-ASA had inactive disease. After seven days of continuous therapy, fasting blood was obtained for 5-ASA and acetyl 5ASA and an in vivo faecal dialysis study was started. During the following 24 hour period, urine was collected to measure 5-ASA excretion while stools were collected for the following 72 hours. Faecal dialysis was carried out as follows: dialysis bags were made by tying off $4 \mathrm{~cm}$ segments of Visking seamless tubing and filled with $1.5 \mathrm{ml}$ Rheomacrodex (Pharmacia) containing 10\% Dextran (mean molecular weight 40000 ) in $0.9 \%$ saline. At each study five bags were swallowed. After intestinal transit the bags were removed from the stools and cleaned with dry Kleenex tissue. The contents were emptied and stored at $-20^{\circ} \mathrm{C}$ for analysis. Those patients on coated 5-ASA continued with full medication until day 21 when the determinations were repeated. The study was approved by the Ethics Committee of Newcastle Health Authority.

Acetyl 5-ASA and 5-ASA in blood plasma, urine, and faecal dialysate were determined by a modification of the method of Dew et al..$^{13}$ The method represents a considerable improvement on previously described procedures and involves the simultaneous measurement of acetyl 5-ASA and 5-ASA after the addition of internal standard without the need for solvent extraction or derivatisation. Plasma or suitably diluted urine or faecal dialysate $(0.5 \mathrm{ml})$ was added to $0.5 \mathrm{ml}$ of methanol containing 54 $\mu$ moles of dihydroxybenzoic acid (DHBA; internal standard) and centrifuged for 15 minutes at $2500 \mathrm{~g}$ in glass stoppered conical tubes. The supernatant was transferred to $1.5 \mathrm{ml}$ plastic stoppered conical tubes and further centrifuged for 10 minutes at $13000 \mathrm{~g}$. An aliquot of the supernatant $(100 \mu \mathrm{l})$ was taken for analysis by high performance liquid chromatography as follows: A Pye-Unicam LC-3 XP pump was connected via a loop injector and a guard column, packed with $\mathrm{C}_{18} /$ Corasil Bondapack reverse phase packing material (Waters), to a LiChrosorb 10 RP18 bonded silica reverse phase column $(2.4 \times 250 \mathrm{~mm}$; Technicol Ltd). The mobile phase was $28 \%$ methanol (v/v), $72 \%$ potassium phosphate $(50 \mathrm{mmol} / \mathrm{l} ; \mathrm{pH} \mathrm{7.4)}$ which contained $0.075 \%(\mathrm{v} / \mathrm{v})$ tetrabutylammonium hydroxide and was degassed by vacuum sonication. The flow rate was $1.8 \mathrm{ml} / \mathrm{min}$. Analytes were detected fluorimetrically using a Perkins-Elmer model 3000 fluorescence spectrometer fitted with a $8 \mu \mathrm{l}$ flow cell with a $2 \mathrm{~mm}$ pathlength. The excitation wavelength was $315 \mathrm{~nm}$ with a bandpass of $10 \mathrm{~nm}$ and the emission wavelength was $485 \mathrm{~nm}$ with a bandpass of
$20 \mathrm{~nm}$. The time constant was 2 seconds. Quantitation was achieved by peak area ratio measurements (analyte to internal standard) using a HewlettPackard integrator (model 3390A) and reference to calibration values obtained with a standard mixture made up in plasma $(0 \cdot 41-4 \cdot 1 \mu \mathrm{mol} / 15$-ASA ; $0.64-$ $6.4 \mu \mathrm{mol} / \mathrm{l}$ acetyl 5-ASA).

Excellent separations of 5-ASA, DHBA and Acetyl 5-ASA were achieved (retention times of $3.62,4.66$, and $6 \cdot 71$ minutes respectively; Fig. 1). Calibration curves were constructed from water and plasma which could be superimposed (Fig. 2). A calibration curve from plasma was constructed at the beginning of each working day and was only used if the correlation coefficient was 0.999 or better. The between batch precision was $2.6 \%$ for Acetyl 5-ASA at a concentration of $1.6 \mu \mathrm{mol} / \mathrm{l}$ and $1.8 \%$ for 5 -ASA at a concentration of $4 \cdot 1 \mu \mathrm{mol} / \mathrm{l}(\mathrm{n}=5)$.

\section{STATISTICAL ANALYSIS}

The results from the patient studies (mean \pm SEM) were analysed by the paired or unpaired two-tailed Student's $t$ test as appropriate. Total ASA refers to the molar sum of 5-ASA and Acetyl 5-ASA. Faecal excretion $/ 24 \mathrm{~h}$ was regarded as faecal dialysate concentration multiplied by total stool weight. No corrections were made for variation in faecal water content.

\section{MATERIALS}

Acetyl-5-amino salicylic acid was a gift, kindly provided by Pharmacia Fine Chemicals Ltd. 5Aminosalicylic acid and 2,4-dihydroxybenzoic acid were obtained from Sigma Chemical Co. HPLCgrade methanol and tetrabutylammonium hydroxide

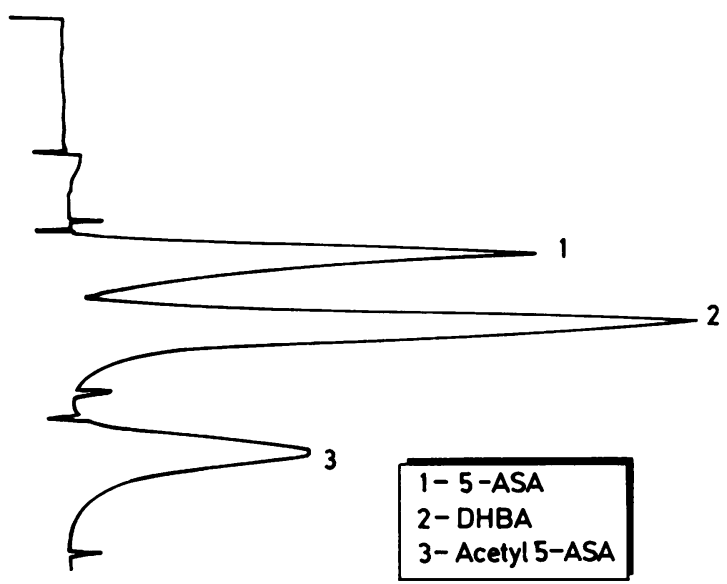

Fig. 1 Chromatogram showing 5-ASA, acetyl 5-ASA and internal standard (dihydroxybenzoic acid; $D H B A$ ).

Retention times were $3 \cdot 62,4.66$ and $6 \cdot 71$ minutes, respectively. 


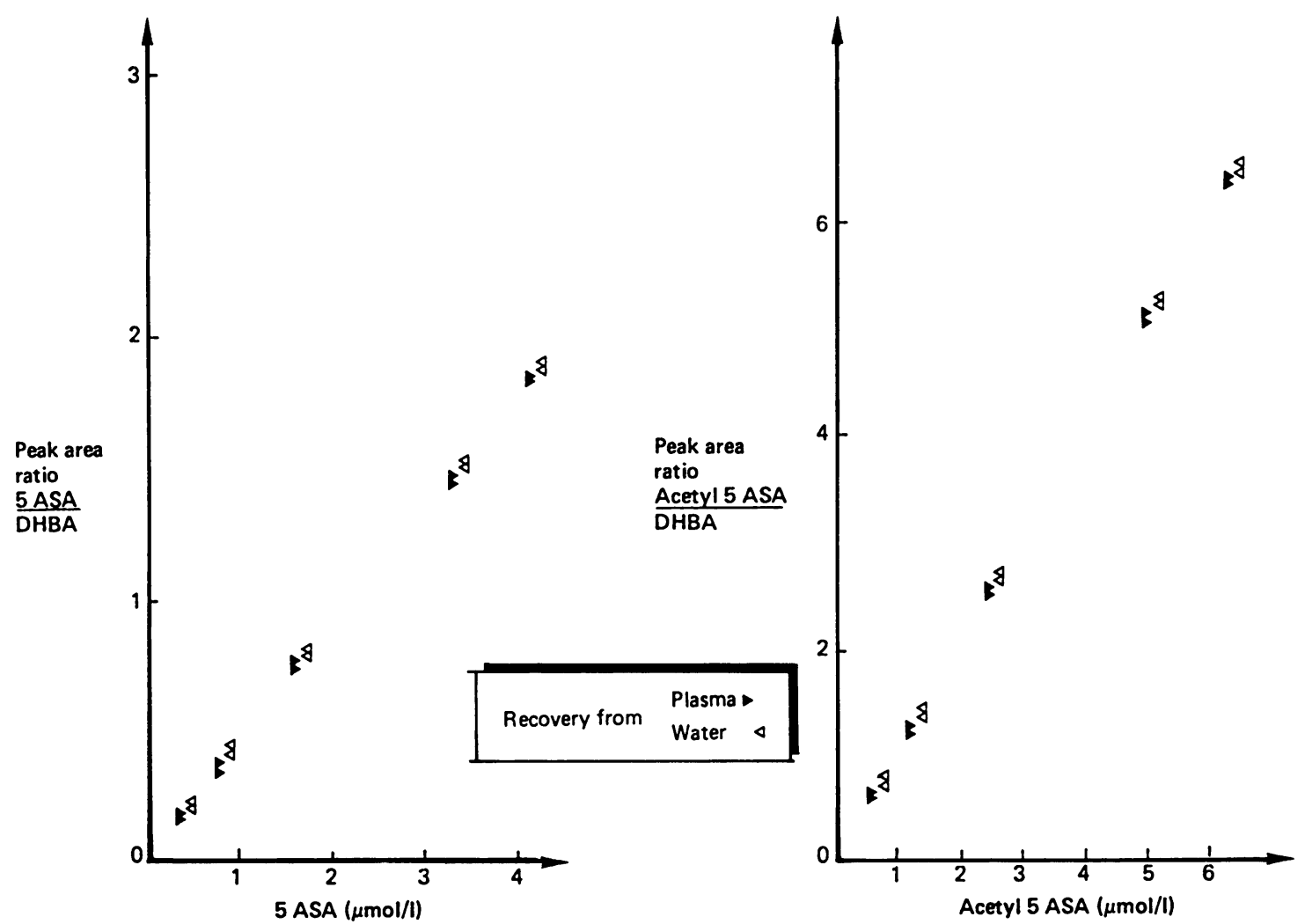

Fig. 2 Standard curve showing recovery of 5-ASA and acetyl 5-ASA from plasma and water. Values are expressed as peak area ratio to internal standard (dihydroxybenzoic acid; $D H B A$ ).

were purchased from Fisons Ltd. All other reagents were of analytical grade.

\section{Results}

Trough concentrations of ASA fractions in the plasma of patients on uncoated 5-ASA were significantly lower than those seen with the coated product after both seven and 21 days of therapy (Fig. 3; Table 1). Urinary excretion, however, $(\mathrm{mmol} / 24 \mathrm{~h})$ was similar in the three groups (Fig. 3; Table 1). The excretion of 5-ASA and total ASA in faeces is shown in Table $1(\mathrm{mmol} / \mathrm{l})$ and Figure $4(\mathrm{mmol} / 24 \mathrm{~h})$. There was a highly significant ( 28 fold) difference in 5-ASA in patients on the coated compared to the uncoated product (Fig. 4) but smaller differences were observed for total ASA because acetyl 5-ASA concentrations were similar in each of the study groups (Table 1). The 21 day faecal dialysate concentration and faecal excretion of 5-ASA and total ASA were significantly lower than seven day values $(p<0) \cdot 05$; Fig. 4).

Plasma concentrations, urine and faecal excretion of total 5-ASA for patients with active and inactive colitis on coated 5-ASA tablets are shown in Table 2. Although in patients with active disease there were substantial differences between seven and 21 day values, and seven day faecal values in patients with inactive disease, these were not significant probably because of the small numbers in each subgroup. The raised seven day faecal excretion in patients with active disease, however, had fallen to a value comparable with that seen in inactive patients after 21 days of therapy. Ninety per cent of the 5-ASA consumed $(10.5 \mathrm{mmol}$ ) was excreted in faeces (as total ASA) after seven days of treatment in patients with active colitis compared with $40 \%$ for patients with inactive colitis. This difference was not significant. Sixty five per cent of the ingested dose appeared in the stools of the patients treated with coated 5 -ASA compared with only $16 \%$ in those receiving the uncoated product (Fig. $4 ; \mathrm{p}<0 \cdot(01)$.

\section{Discussion}

These results confirm that the $\mathrm{pH}$ dependent polymer coating of 5-ASA is a highly successful method for delivering total ASA (5-ASA and the metabolite 
Table 1 ASA fractions in plasma, urine and faeces after seven days of polymer coated or uncoated 5-amino salicylic acid. Mean $\pm S E M$ with the number of observations in parentheses

\begin{tabular}{|c|c|c|c|c|c|c|c|}
\hline \multicolumn{2}{|l|}{ Plasma $\mu \mathrm{mol} / \mathrm{l}$} & \multicolumn{2}{|c|}{ Urine $\mathrm{mmol} / 24 \mathrm{~h}$} & \multicolumn{2}{|c|}{ Faecal dialysate mmol/l } & \multicolumn{2}{|c|}{ Faecal excretion (mmol/24h) } \\
\hline $5-A S A$ & Acetyl 5-ASA & $5-A S A$ & Acetyl5-ASA & $5-A S A$ & Acetyl5-ASA & $5-A S A$ & Acetyl $5-A S A$ \\
\hline $\begin{array}{l}\text { Coated ASA } \\
11 \cdot 1(15) \\
\pm 4 \cdot 2\end{array}$ & $\begin{array}{l}13 \cdot 3(15) \\
\pm 3 \cdot 2\end{array}$ & $\begin{array}{l}0 \cdot 34(15) \\
\pm(0 \cdot 21\end{array}$ & $\begin{array}{l}0 \cdot 83(15) \\
\pm 0 \cdot 19\end{array}$ & $\begin{array}{l}25 \cdot 4(15) \\
\pm 5 \cdot 1\end{array}$ & $\begin{array}{l}10 \cdot 5(15) \\
\pm 2 \cdot 1\end{array}$ & $\begin{array}{l}4 \cdot 7(10) \\
\pm 0 \cdot 9\end{array}$ & $\begin{array}{l}2 \cdot()(10) \\
\pm(0 \cdot 5\end{array}$ \\
\hline $\begin{array}{l}\text { Uncoated ASA } \\
0 \cdot 07(8) \\
\pm 0 \cdot 03\end{array}$ & $\begin{array}{l}2.7(8) \\
\pm 0.5\end{array}$ & $\begin{array}{l}0 \cdot 70(8) \\
\pm 0 \cdot 29\end{array}$ & $\begin{array}{l}1 \cdot 7(8) \\
\pm 0 \cdot 6\end{array}$ & $\begin{array}{l}1 \cdot 2(8) \\
\pm 0 \cdot 4\end{array}$ & $\begin{array}{l}10 \cdot 4(8) \\
\pm 1 \cdot 8\end{array}$ & $\begin{array}{l}(0 \cdot 2(8) \\
\pm 0 \cdot(05\end{array}$ & $\begin{array}{l}1 \cdot 5(8) \\
\pm 0 \cdot 3\end{array}$ \\
\hline $\mathrm{p}<0 \cdot 02$ & $0 \cdot 01$ & NS & NS & $<0 \cdot 001$ & NS & $<0 \cdot(001$ & NS \\
\hline
\end{tabular}

acetyl 5-ASA) to the colon, a four fold increase compared with the uncoated product being observed. This difference is even more marked ( 28 fold) when 5-ASA alone is considered as acetyl 5-ASA concentrations in the two groups were not significantly different. The difference between faecal excretion of the drug and its metabolite could be clinically significant as acetyl 5-ASA is probably inactive in ulcerative colitis when administered by enema. ${ }^{14}$ In animal studies orally administered uncoated 5-ASA undergoes absorption in the proximal small intestine, is acetylated and $60 \%$ is excreted in urine and $6 \%$ in bile. ${ }^{1}$ The present studies indicate that polymer coating probably retards jejunal absorption as urinary excretion was about $50 \%$ of that seen with the uncoated product, although in these human studies only about $23 \%$ of the uncoated product was excreted in urine in a $24 \mathrm{~h}$ period. The latter is in close

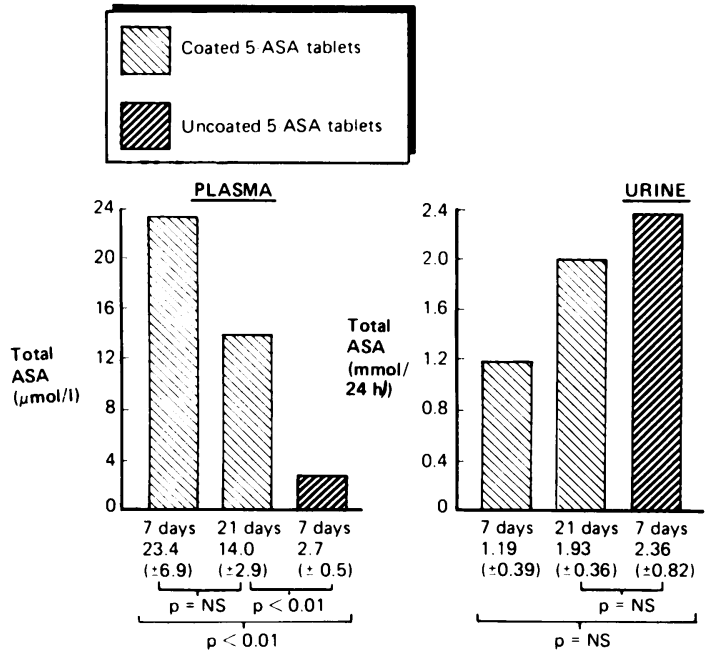

Fig. 3 Plasma concentration and urinary excretion of total $A S A$ (5-ASA + acetyl 5-ASA) after polymer coated and uncoated 5-amino salicylic acid therapy of seven or 21 days duration. agreement with previous studies in man which also showed that urinary excretion of ASA after polymer coated 5-ASA $(20 \%)$ was similar to that seen after an equivalent dose of sulphasalazine $(25 \%){ }^{13}$ The significantly higher concentrations of ASA in the plasma of patients on coated 5-ASA is probably also a reflection of delayed absorption as blood samples were taken 12 hours after the last oral dose. The continuing absorption at this time may have been because of terminal ileal absorption after release at this site or perhaps slow colonic absorption. Dew et $a l^{13}$ have shown peak serum concentrations six hours after a single oral dose of polymer coated 5-ASA which were up to 3.5 times higher than after sulphasalazine. In the present studies, however, no further increase in the seven day plasma concentration of ASA was found after 21 days of therapy.

Polymer coating enables delivery of unmodified

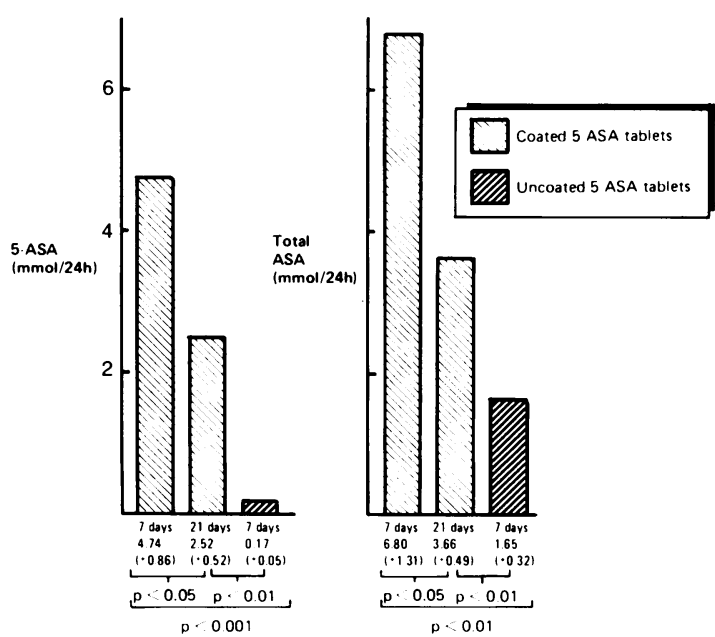

Fig. 4 Faecal excretion (dialysate concentration $\times$ stool weight) of 5-ASA and total $A S A$ (5- $A S A+$ acetyl $5-A S A)$ after polymer coated and uncoated 5-amino salicylic acid therapy of seven or 21 days duration. 
Table 2 Total ASA plasma concentrations, urinary and faecal excretion for patients with active and inactive colitis receiving coated 5-ASA. Mean $\pm S E M$ with the number of observations in parentheses

\begin{tabular}{|c|c|c|c|c|c|}
\hline \multicolumn{2}{|c|}{ Plasma umol/l } & \multicolumn{2}{|c|}{ Urine mmol/24h } & \multicolumn{2}{|c|}{ Faeces mmol/24h } \\
\hline 7 days & 21 days & 7 days & 21 days & 7 days & 21 days \\
\hline $\begin{array}{l}\text { Active } \\
28 \cdot 6(9) \\
( \pm 30 \cdot 3)\end{array}$ & $\begin{array}{l}12 \cdot 3(7) \\
( \pm 1(0 \cdot 6)\end{array}$ & $\begin{array}{l}1 \cdot 3(9) \\
( \pm 2 \cdot 0)\end{array}$ & $\begin{array}{l}2 \cdot 1(6) \\
( \pm 1 \cdot 4)\end{array}$ & $\begin{array}{l}9 \cdot 6(5) \\
( \pm 3 \cdot 3)\end{array}$ & $\begin{array}{l}3 \cdot 7(4) \\
( \pm 1 \cdot 4)\end{array}$ \\
\hline $\begin{array}{l}\text { Inactive } \\
15 \cdot 7(6) \\
( \pm 20 \cdot 1)\end{array}$ & $\begin{array}{l}15 \cdot 9(6) \\
( \pm 10 \cdot 8)\end{array}$ & $\begin{array}{l}1 \cdot 0(6) \\
( \pm 0 \cdot 5)\end{array}$ & $\begin{array}{l}1 \cdot 7(6) \\
( \pm 1 \cdot 2)\end{array}$ & $\begin{array}{l}4 \cdot 0(5) \\
( \pm 2 \cdot 9)\end{array}$ & $\begin{array}{l}3 \cdot 6(4) \\
( \pm 1.5)\end{array}$ \\
\hline $\mathrm{p}=\mathrm{NS}$ & $p=N S$ & $\mathrm{p}=\mathrm{NS}$ & $\mathrm{p}=\mathrm{NS}$ & $\mathrm{p}=\mathrm{NS}$ & $\mathrm{p}=\mathrm{NS}$ \\
\hline
\end{tabular}

5-ASA to the colon where the drug can exert a local anti-inflammatory effect. The importance of the local action of the drug has been confirmed in clinical practice by the efficacy of 5-ASA retention enemas upon healing of inflammatory changes in the rectum..$^{15}$ Campieri et al' found significantly higher concentrations of acetyl 5-ASA in the urine of patients with disease in remission compared with active disease and used this observation to argue that 5-ASA exerts its therapeutic benefit locally. In the present study, faecal excretion at seven days was higher in patients with active disease, probably because of impaired absorption of the drug by inflamed colonic mucosa, although this failed to reach statistical significance $(\mathrm{p}<0 \cdot 1)$. Christensen et al showed decreased absorption in patients with accelerated transit time using a slow release preparation of $5-\mathrm{ASA}^{17}$ but intestinal transit in active ulcerative colitis and controls has recently been been shown to be similar. ${ }^{10}$ The decreased faecal and increased urinary excretion in patients with active disease after 21 days compared with seven days of therapy suggests an increase in colonic absorption with resolution of mucosal inflammation.

Several analogues of sulphasalazine are now available, each attempting to be as efficacious as the original compound without the concomitant side effects. Some, such as sodium azodisalicylate continue to rely on the azo-bond. Although this compound is as effective as sulphasalazine, in a large Swedish trial of 160 patients at least one side effect (such as loose stool, nausea, and skin rash) was seen in $33 \%$ of those treated.' It may be that the azo-bond itself is responsible for many of the side effects. Acrylic resin coating of 5-ASA in a preparation such as used in this study, which has been shown to release 5-ASA in the ileum and caecum at pH 7 or above, provides a valuable and potentially less toxic alternative $^{19}$ no adverse effects being encountered in the present study.
In conclusion, 5-ASA coating with methacrylic acid copolymer B (Eudragit $S$ ) provides a valuable means of promoting delivery of the drug to its colonic site of action. It may be that polymer coated 5-ASA is better tolerated than traditional and modern azobond molecules, although further comparative trials of both patient acceptability and therapeutic efficacy are required.

This study was made possible by a grant from Tillotts Laboratories Ltd, UK.

\section{References}

1 Friedman G. Sulfasalazine and new analogues. $A m J$ Gastroenterol 1986; 81: 141-5.

2 Pepperman MA, Goldman P. Distribution studies of salicylazosulfapyridine and its metabolites. Gastroenterology 1973; 64:240-5.

3 Azad Khan AH, Piris J, Truelove SC. An experiment to determine the active therapeutic moeity of sulphasalazine. Lancet 1977; ii: 892-5.

4 Van Hees PAM, Bakker JH, Van Tougeren JHM. Effect of sulphapyridine, 5-aminosalicylic acid, and placebo in patients with idiopathic proctitis: a study to determine the active therapuetic moeity of sulphasalazine. Gut 1980; 21: 632-5.

5 Klotz U, Mainer K, Fischer C, Heinkel K. Therapeutic efficacy of sulfasalazine and its metabolites in patients with ulcerative colitis and Crohn's disease. N Engl J Med 1980; 303: 1499-502.

6 Dew MJ, Ryder REJ, Evans M, Evans BK, Rhodes J. Colonic release of 5-amino salicylic acid from an oral preparation in active ulcerative colitis. $\mathrm{Br} J$ Clin Pharmacoe 1983; 16: 185-7.

7 Dew MJ, Hughes P, Harries AD, Williams G, Evans $\mathrm{BK}$, Rhodes $\mathbf{J}$. Maintenance of remission in ulcerative colitis with oral preparation of 5-aminosalicylic acid. $\mathrm{Br}$ Med J 1982; 285: 1012.

8 Dew MJ, Harries AD, Evans N, Evans BK, Rhodes AJ. Maintenance of remission in ulcerative colitis with 5 -aminosalicylic acid in high doses by mouth. Br Med J 1983; 287: 23-4.

9 Dew MJ. Harries AD, Evans BK, Rhodes J. Treatment of ulcerative colitis with oral 5-aminosalicylic acid in patients unable to take sulphasalazine. Lancet 1983; ii: 801.

10 Shaffer JL, Kershaw A, Berrisford MH. Sulphasalazineinduced infertility reversed on transfer to 5aminosalicylic acid. Lancet 1984; ii: 1240.

11 Cann PA, Holdsworth CD. Reversal of male infertility on changing treatment from sulphasalazine to 5-aminosalicylic acid. Lancet 1984 ; i: 1119.

12 Austin CA, Cann PA, Jones TH, Holdsworth CD Exacerbation of diarrhoea and pain in patients treated with 5-aminosalicylic acid for ulcerative colitis. Lancet 1984; i: 917. 
13 Dew MJ, Ebden P, Kidwai NS, Lee G, Evans BK. Rhodes J. Comparison of the absorption and metabolism of sulphasalazine and acrylic-coated 5aminosalicylic acid in normal subjects and patients with colitis. Br J Clin Pharmacol 1984; 17: 474-6.

14 Binder V, Halskov S, Hvidberg E, et al. A controlled study of 5-acet-aminosalicylic acid as enema in ulcerative colitis. Scand J Gastroenterol 1982; 16: 1122.

15 Campieri M, Lanfranchi GA, Bazzocchi G, et al. Treatment of ulcerative colitis with high dose 5aminosalicylic acid enemas. Lancet 1981; ii: 270-1.

16 Campieri M, Lanfranchi GA, Boschi S, et al. Topical administration of 5-aminosalicylic acid enemas in patients with ulcerative colitis. Studies on rectal absorption and excretion. Gut 1985; 26: 400-5.

17 Christensen LA, Slot O, Sanchez G, et al. 5-ASA release from Pentasa during normal and accelerated intestinal transit time. Proceedings of the 18th European Congress of Gastroenterology and Endoscopy. Hepatato-Gastroenterology 1986 (In press).

18 Rao SSC, Read NW, Holdsworth CD. Gastrointestinal transit and stool output in the pathophysiology of diarrhoea in ulcerative colitis. Clin Sci 1986; 71: 41.

19 Klotz U. Clinical efficacy of oral 5-aminosalicylic acid in the treatment of inflammatory bowel disease. Am J Gastroenterol 1985; 80: 660. 